\title{
Chemical defense in a scyphomedusa
}

\author{
Alan L. Shanks ${ }^{1}$, William M. Graham ${ }^{2}$ \\ ${ }^{1}$ University of North Carolina at Chapel Hill, Institute of Marine Sciences, 3407 Arendell St, Morehead City, North Carolina \\ 28557, USA \\ ${ }^{2} 215$ N Fifth St, Danville, Kentucky 40422, USA
}

\begin{abstract}
The scyphozoan Stomolophus meleagris, when disturbed (held in a container), discharges a sticky mucus. Toxins released into the mucus and water kill some fish and crustaceans and can immediately alter fish behavior, but did not affect a crab predator of $S$. meleagris. The mucus contains discharged and undischarged nematocysts. The toxins in the mucus are probably associated with these nematocysts. In the field. $S$. meleagris subjected to a simulated small predator bite released clouds of nematocysts which drove off small fish (potential predators), but did not drive off the associated predacious crabs. These 2 behaviors appear to be forms of chemical defense. Two other species of scyphozoans and a ctenophore species also discharge mucus when disturbed. Chemical defenses may be common amongst gelatinous zooplankton.
\end{abstract}

\section{INTRODUCTION}

Due to their high water and low carbon content (Curl 1962, Beers 1966) gelatinous zooplankton appear to be a poor food. However, the food value of the nongelatinous parts of these organisms (e.g. gonads, feeding structures, stomach) can be quite high, and because gelatinous zooplankton are often large, the amount of quality food represented by the non-gelatinous parts is also large (Shenker 1985). For example, the gonads of a jellyfish can weigh about $8 \mathrm{~g}$ and have a carbon content equivalent to that of a larval fish (Curl 1962, Beers 1966, Shenker 1985). In fact, some predators of gelatinous zooplankton consume only these more nutritious parts (Harbison et al. 1977, Madin \& Harbison 1977. Janssen \& Harbison 1981). Several characteristics shared by gelatinous zooplankton may help thwart predation, i.e. low overall food value, complex and alternating life cycles, transparency, and escape behaviors. Many organisms in terrestrial (Rosenthal \& Janzen 1979) and benthic marine habitats (Bakus 1981) utilize chemical defenses. One common form of chemical defense is the discharge of a repellent, often sticky, chemical upon attack (Thompson 1960, Tursch 1982, Faulker \& Ghiselin 1983), a defense also utilized by some freshwater planktonic arthropods (Kerfoot 1982).

The thoughts in the preceding paragraph were inspired by the following observations. A diver gently caught a Stomolophus meleagris (Scyphozoa, Rhizostomida) and its associated fish in a bucket. During

(c) Inter-Research/Printed in F. R. Germany capture the fish hid inside the bell of their host. Immediately after the bucket was set on deck the jellyfish began discharging mucus whereupon the fish abandoned their sanctuary and died within minutes. Copepods (caught incidentally) contacting the mucus died instantly while those avoiding the mucus died more slowly. Neither the fish nor copepods appeared to have contacted the very short tentacles of the jellyfish. These events are similar to descriptions of chemical defenses in soft corals (Tursch 1982). Toxins released with the mucus discharged by $S$. meleagris may be a form of chemical defense. If this is so then one would predict that the released chemicals would be an effective deterrent to predation (i.e. toxic) and would be mobilized upon disturbance (Faulkner \& Ghiselin 1983).

\section{METHODS AND RESULTS}

The jellyfish Stomolophus meleagris is common in the nearshore waters of Onslow Bay, North Carolina, USA, where this study took place. By early summer most (about $80 \%$ ) of the S. meleagris are inhabited by juvenile planehead filefish Monacanthus hispidus and Atlantic bumpers Chloroscombrus chrysurus. The smaller bumpers are often found hiding under the bell of the jellyfish between the scapulets. Upon the approach of a diver, bumpers which were observed swimming around the jellyfish quickly sought shelter between the scapulets. Juvenile planehead filefish 
were usually observed swimming immediately behind the center of the oral disk. If the jellyfish was undisturbed, these juvenile fish remained hiding in the jellyfish and appeared to suffer no harm from this close association. Immediately after capture a number of planehead filefish and Atlantic bumpers were killed and preserved in formalin. Stomachs of all of the planehead filefish ( $n=5$ ) and most Atlantic bumpers (5 of 8) examined contained discharged nematocysts and crustaceans. No pieces of jellyfish tissue were observed. This suggests that these juvenile fish consume prey stunned by the jellyfish and that they may not consume the jellyfish itself. In some instances, however, juvenile fish associated with jellyfish have been observed to consume their jellyfish host (Mansueti 1963).

About $20 \%$ of the Stomolophus meleagris were also inhabited by the spider crab Libinia dubia. Crabs usually were found under the bell, in pits they had excavated in the scapulets. While diving we observed crabs apparently feeding on the tentacles of the oral disk. The cardiac stomach of the examined L. dubia $(n=5)$ contained numerous pieces of jellyfish tissue and tentacles: L. dubia consumes its host.

The effectiveness of a chemical defense was tested in the ocean. A diver approached a Stomolophus meleagris, frightening the associated fish (planehead filefish and Atlantic bumpers) into the bell of the jellyfish. After several minutes of observation to determine if the sheltering fish were harmed, the diver, attempting to simulate an attack of a small predator, pinched the jellyfish along the bell margin with forceps. Because of a vigorous escape response (Shanks \& Graham 1987) the jellyfish was held at arm's length with the forceps. The diver was not in physical contact with the jellyfish and his head and shoulders were about $1 \mathrm{~m}$ behind the jellyfish.

Ten jellyfish were tested with identical results. Prior to pinching, none of the fish left their shelter nor did they appear to suffer any ill effects. Previous observations suggest that, in fact, many fish reside inside the jellyfish even when unthreatened. After being pinched, none of the disturbed jellyfish discharged mucus as they do when caught in a bucket. However, within a minute the diver experienced numerous painful stings about the head and shoulders. At the same moment that the diver was stung, all of the fish simultaneously abandoned their hosts and swam rapidly away. Two jellyfish were also host to the spider crab Libinia dubia. Following pinching of the jellyfish, the crabs did not abandon their host, but crawled out from under the bell and onto the exterior and most forward part of the bell.

The pinched jellyfish apparently released a cloud of undischarged nematocysts. It should be noted that the simulated bite differed from a natural bite of a predator; we held the jellyfish with the forceps after pinching them. The stimulus may not accurately mimic a predator's bite, but the disturbance initiated a behavior which obviously and dramatically had the capacity to drive off small fish (potential predators), but did not drive off the associated predacious crabs. It might be argued that the fish abandoned their host as a reaction to the jellyfish's flight response. Each jellyfish began a vigorous escape immediately upon being pinched while nematocyst discharge occurred 30 to $60 \mathrm{~s}$ later. The associated fish remained with their host during its initial flight response, but simultaneously abandoned the jellyfish upon the release of nematocysts. This suggests that the fish left the jellyfish in response to nematocyst release.

Attempts to stimulate mucus discharge by jellyfish in the ocean by pinching or even rough handling were unsuccessful. However, specimens disturbed by catching them in a bucket immediately discharged mucus. Even pieces of Stomolophus meleagris discharge mucus. A plastic bag was placed around the scapulets of a $S$. meleagris which was discharging mucus. When the bag was removed there was no mucus on the inside of the bag, but the outside was covered. Thus the mucus is discharged from the underside of the bell. If this behavior is a form of chemical defense then it should be capable of deterring predation and this might be accomplished if chemicals released with the mucus were toxic.

Mucus was collected by placing one Stomolophus meleagris (ca $500 \mathrm{ml}$ vol) in a $4 \mathrm{l}$ jar of seawater. The jellyfish immediately began discharging mucus. The individual was held in the jar for 20 min, and was further disturbed by pinching its bell margin with forceps. The jellyfish was removed, the water stirred, and $200 \mathrm{ml}$ aliquots withdrawn. Half the aliquots were centrifuged at $8000 \times g$ for $15 \mathrm{~min}$ to remove particulates and pieces of mucus (Toom \& Chan 1972). The behavior of animals in $200 \mathrm{ml}$ aliquots of mucus/seawater and seawater from which the mucus and particulates were removed (mucus-free) was followed for 1 to $2 \mathrm{~h}$ and compared to animals in clean seawater $(200$ $\mathrm{ml}$ ). There were 3 replicates of each treatment, 1 animal per replicate and 4 species tested. Three of the species tested associate with $S$. meleagris in the wild. These are juvenile planehead filefish, Atlantic bumpers, and spider crabs. The fourth species, the pinfish Lagodon rhomboides, does not associate with jellyfish. The fish were 3 to $5 \mathrm{~cm}$ total length. The spider crabs were 2 to $4 \mathrm{~cm}$ in carapace width. The experiments on the different species were run on separate days using new jellyfish and some experiments required mucus from more than one jellyfish

All fish in the experimental treatments immediately appeared stressed. They were very active, gaped at the surface and soon lay on the bottom (Fig. 1). No animals 

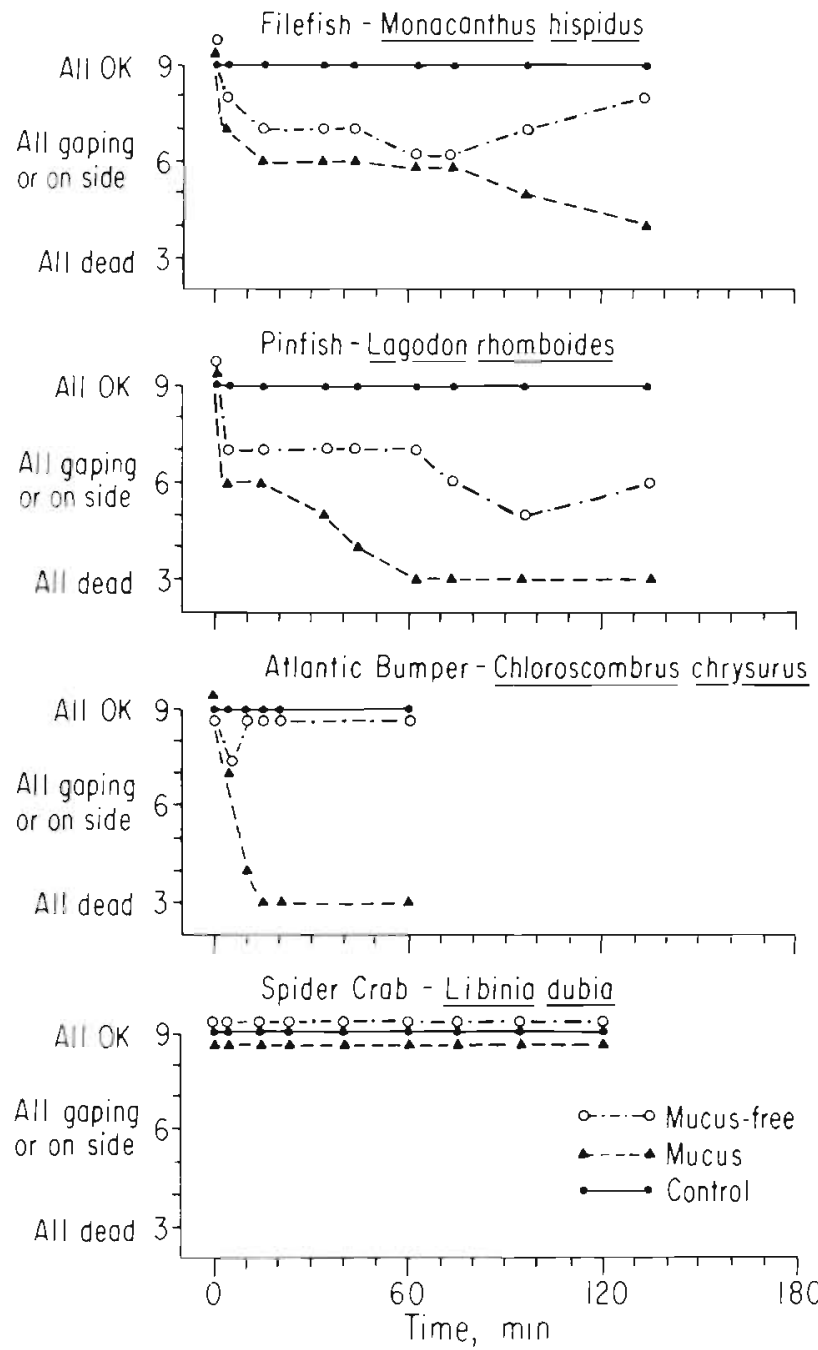

Fig. 1. Responses of 3 species of fish and a crab to mucus from the jellyfish Stomolophus meleagris. Mucus-free is water in which mucus was discharged and then removed by centrifugation. Control is clean seawater. There were 3 replicates with 1 individual each for all treatments. Response of each animal was scored (normal $=3$, stressed $=2$, dead $=1$ ) and the sum of the scores of the 3 replicate animals are plotted in the figure in the seawater controls appeared stressed. By the end of the experiment, two of the planehead filefish in the mucus/seawater treatment were dead and the third, visibly stressed, died overnight in clean seawater. In the mucus-free treatment all of the planehead filefish appeared stressed at $1 \mathrm{~h}$, but by the end, only one appeared so. By $1 \mathrm{~h}$ all the pinfish in mucus/seawater were dead. In the mucus-free treatments, 1 pinfish died and a second, still stressed at the end of the experiment, died overnight in clean seawater. All the Atlantic bumpers in mucus/seawater died within $15 \mathrm{~min}$, but the mucus-free treatment affected behavior only during the first minutes. The spider crabs were unaffected by the treatments.

Stomolophus meleagris releases toxins into both the water and discharged mucus. The mucus is extremely sticky, rapidly trapping particulates in the water (including protozoans, which are not killed). The mucus sticks to fish. Post-mortem examination of fish killed by the mucus/seawater treatments found mucus on the fish's gills with nematocysts discharged into the gill surface.

Using the same species (new individuals) the hyperactivity resulting from contact with mucus/seawater was quantified by comparing the number of quadrats crossed $(10 \times 10 \mathrm{~cm}$ tank $)$ in $1 \mathrm{~min}$ by an individual in mucus/seawater (produced as in the previous experiment using new jellyfish) with its activity in a seawater control. Each individual was randomly assigned to an initial treatment. After the 1 min treatment exposure, each individual was placed in clean seawater for $1 \mathrm{~h}$ and then exposed to the alternate treatment. The responses of animals in the 2 treatments were statistically compared using a paired t-test.

Neither spider crabs nor planehead filefish were more active in mucus/seawater than the control (Table 1); however, 3 of 8 planehead filefish tested lay on the bottom part of the time. Both pinfish and Atlantic bumpers were significantly $(p<0.02)$ and about twice as

Table 1. Effect of mucus discharged by disturbed Stomolophus meleagris on the activity of 3 species of juvenile fish and a crab

\begin{tabular}{|c|c|c|c|c|}
\hline \multirow[b]{2}{*}{ Species } & \multicolumn{4}{|c|}{ Average no. of quadrats crossed min ${ }^{-1}$} \\
\hline & Mucus/seawater & Seawater & $t^{\cdot}$ & $p$ \\
\hline $\begin{array}{l}\text { Planehead filefish Monacanthus hispidus } \\
\qquad n=8\end{array}$ & 20 & 20 & -0.1 & $>0.10$ \\
\hline $\begin{array}{l}\text { Spider crab Libinia dubia } \\
\qquad n=12\end{array}$ & 2 & 3 & -0.2 & $>0.10$ \\
\hline $\begin{array}{l}\text { Atlantic bumper Chloroscombrus chrysurus } \\
\qquad n=8\end{array}$ & 16 & 9 & 3.1 & $<0.02$ \\
\hline $\begin{array}{l}\text { Pinfish Lagodon rhomboides } \\
\qquad n=7\end{array}$ & 26 & 10 & 6.9 & $<0.001$ \\
\hline
\end{tabular}


active in the mucus/seawater treatment than in the control (Table 1). This was despite the fact that 2 of 8 Atlantic bumpers tested also spent time lying on the bottom. Thus the toxin released during mucus discharge can immediately alter the behavior of some fish.

Viewed under the microscope, the mucus is found to be peppered with discharged and undischarged nematocysts as well as intact nematocysts bearing tentacles (Fig. 2). The toxin associated with the mucus may be undischarged nematocysts while the toxin in the water may be nematocyst toxin released by discharged nematocysts. The major effects of Stomolophus meleagris nematocysts toxin have been found to be dermonecrotic, hemolytic and cardiovascular (Toom et al. 1976). The natural stimulus for mucus discharge is unknown. Perhaps mucus discharge is a defense against predators (e.g. large fish) which attempt to bite large pieces from the jellyfish or consume smaller indi-
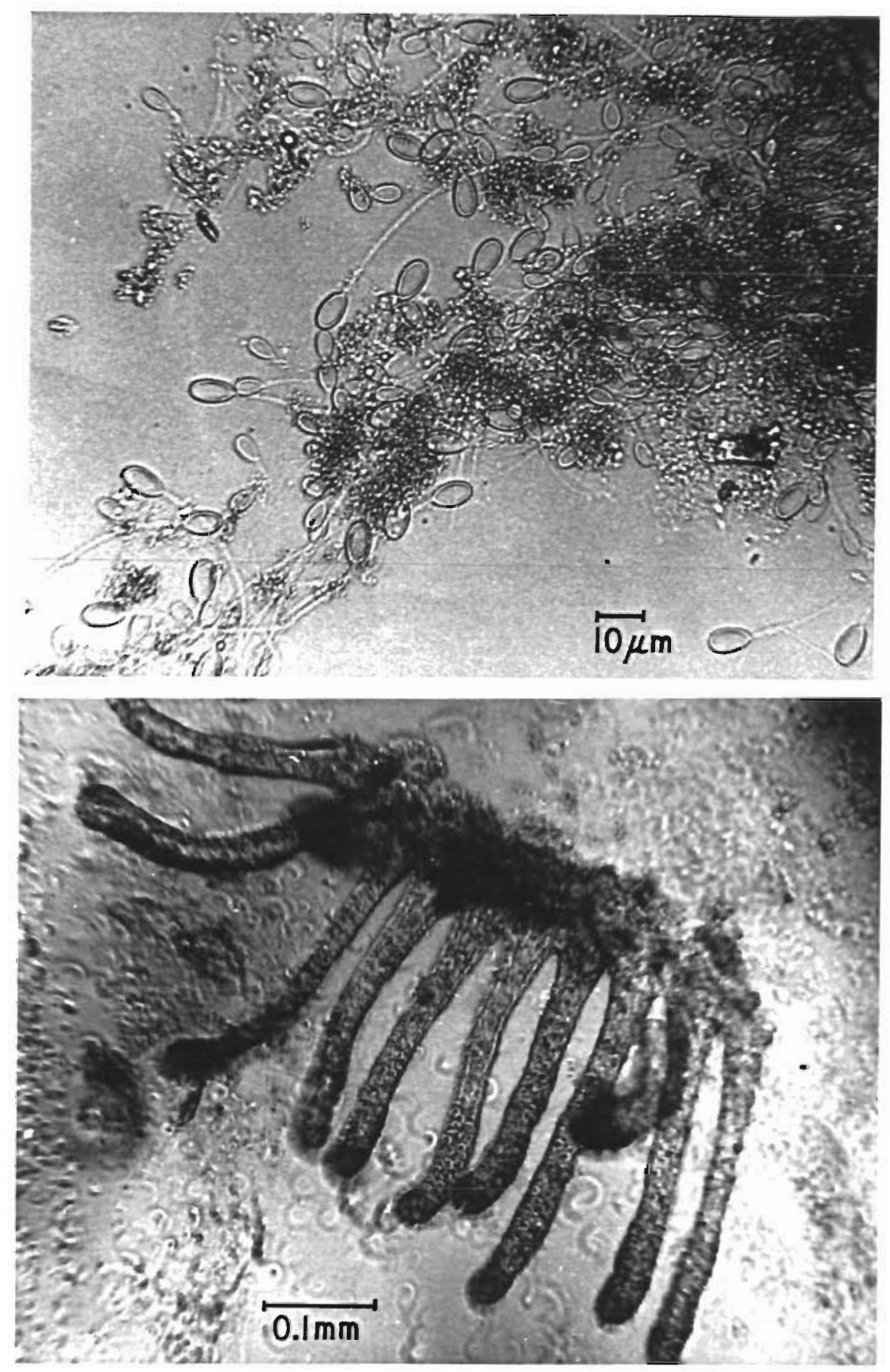

Fig. 2. Stomolophus meleagris 1 crographs of mucus discharged, containing (upper) numerous discharged nematocysts and (lower) tentacles with undischarged nematocysts 
viduals whole. In either case mucus and associated nematocyst discharge might occur in the predator's mouth. If mucus stuck to the gills of a fish then discharge of the mucus-bound nematocysts would be directly into blood returning to the heart and this could lead to significant physical damage to the predator.

Preliminary observations were made on several other gelatinous zooplankton. The jellyfish Chrysaora quinquecirrha did not discharge mucus when placed in a bucket, but would when pinched. The mucus contained nematocysts and pieces of tentacle. Like Stomolophus meleagris, an Aurelia aurita caught in a bucket immediately discharged mucus and within minutes the associated fish (2 planehead filefish and 2 Atlantic bumpers) were dead. Examined under the microscope this mucus was found to contain discharged and undischarged nematocysts and pieces of nematocyst-bearing tentacle. The ctenophore Mnemiopsis leidyi discharges mucus when pinched or touched with a tentacle from $C$. quinquecirrha, one of its predators.

\section{DISCUSSION}

The gelatinous zooplankton are phylogenetically diverse (5 phyla). Despite this diversity they share several general characteristics: they swim relatively slowly, have limited sensory abilities, have no hard protective coverings, and, because of their size, represent a large concentrated source of food (Shenker 1985). This study suggests that at least some gelatinous zooplankton have evolved chemical defenses. The evidence is clearest for the jellyfish Stomolophus meleagris. When this jellyfish was disturbed by a simulated small predator bite (a pinch with forceps) it released a cloud of undischarged nematocysts which immediately drove off small fish associating with the jellyfish. Mucus discharge also appears to be a form of chemical defense. The mucus is discharged only when the jellyfish is disturbed (e.g. placed in a container), and the mucus is highly toxic; the mucus contains numerous undischarged and discharged nematocysts. Preliminary observations indicate that several other gelatinous zooplankton discharge mucus and nematocysts or colloblasts when disturbed suggesting that they may also utilize chemical defenses. The ctenophore Pleurobrachia pileus also discharges mucus after contacting jellyfish tentacles (Greve 1972) and oceanic ctenophores will discharge sheets of mucus when touched (Caron et al. 1982). The mucus coating the tentacles of at least one ctenophore species contains a toxin (Horridge 1965). Mnemiopsis leidyi mucus contains discharged and undischarged colloblasts as well as pieces of colloblast-bearing tentacle - contents analo- gous to that in jellyfish mucus. Chemical defenses may be common amongst gelatinous zooplankton.

The spider crab Libinia dubia, a common associate and predator of Stomolophus meleagris, is fairly tolerant of the chemical defenses employed by $S$. meleagris. The clouds of nematocysts released by disturbed S. meleagris did not cause $L$. dubia to abandon its host; the crabs simply crawled onto the top of the bell, as far away from the released nematocysts as possible. The lab experiments demonstrated that, unlike the fish tested, discharged mucus did not kill or visibly alter the behavior of $L$. dubia. These spider crabs appear to counter or at least tolerate the chemical defenses of its host and prey S. meleagris. If chemical defenses exist in other gelatinous zooplankton then the associated zooplankton predators (i.e. hyperiid amphipods and fish) may, like $L$. dubia, have evolved methods to counter these defenses. In fact, some hyperiid amphipods and a pycnogonid have been observed to consume the tentacles of scyphozoans (Harbison et al. 1977, Child \& Harbison 1986).

Acknowledgements. This paper greatly benefited from comments and discussion with Drs Dan Rittschof and Mark Hay. The illustrations were provided by $\mathrm{V}$. and $\mathrm{H}$. Page.

\section{LITERATURE CITED}

Bakus, J. J. (1981). Chemical defense mechanisms on the Great Barrier Reef, Australia. Science 211:497-499

Beers, J. R. (1966). Studies on the chemical composition of the major zooplankton groups in the Sargasso Sea off Bermuda. Limnol. Oceanogr. 11: 520-528

Caron, D. A., Davis, P. G., Madin, L. P., Sieburth, J. McN (1982). Heterotrophic bacteria and bacterivorous protozoa in oceanic macroaggregates. Science 218: 795-797

Child, A. C., Harbison, G. R. (1986). A parasitic association between a pycnogonid and a scyphomedusa in midwater J. mar biol. Ass. U. K. 66: 113-117

Curl, H. (1962). Standing crops of carbon, nitrogen, and phosphorus and transfer between trophic levels, in continental shelf waters south of New York. Rapp. P.-v. Réun. Cons. int Explor. Mer 153: 183-189

Faulker, D. J., Ghiselin, M. T. (1983). Chemical defense and evolutionary ecology of dorid nudibranchs and some other opisthobranch gastropods. Mar. Ecol. Prog. Ser. 13: 295-301

Greve, W. (1972). Ökologische Untersuchungen an Pleurobrachia pileus II. Laboratoriumsuntersuchungen. Helgoländer wiss. Meeresunters. 23: 141-164

Harbison, G. R., Biggs, D. C., Madin, L. P. (1977). The association of Amphipoda Hyperiidea with gelatinous zooplankton. II. Associations with Cnideria, Ctenophora, and Radiolaria. Deep Sea Res. 24: 465-488

Horridge, G. A. (1965). Non-motile sensory cilia and neuromuscular functions in a ctenophore independent effector organ. Proc. R. Soc. (Ser b) 162:335-350

Janssen, J., Harbison, G. R. (1981). Fish in salps: The association of square tails (Tetragonurus spp.) with pelagic tunicates. J. mar. biol. Ass. U. K. 61: 917-927

Kerfoot, W. C. (1982). A question of taste: crypsis and warning 
coloration in freshwater zooplankton communities. Ecology 63: 538-554

Madin, L. P., Harbison, G. R. (1977). The association of Amphipoda Hyperiidea with gelatinous zooplankton. I. Association with Salpidae. Deep Sea Res. 24:449-463

Mansueti, R. (1963). Symbiotic behavior between small fishes and jellyfishes, with new data on that between the Stromateid, Peprilus alepidotus, and the Scyphomedusa Chrysaora quinquecirrha. Copeia 1:40-80

Rosenthal, G. A., Janzen, D. M. (1979). Herbivores: their interaction with secondary plant metabolites. Academic Press, New York

Shanks, A. L., Graham, W. M. (1987). Orientated swimming in the jellyfish Stomolophus meleagris L. Agassiz (Scyphozoan, Rhizostomida). J. exp. mar. Biol. Ecol. 108: 159-169
Shenker, J. M. (1985). Carbon content of the neritic scyphomedusa Chrysaora fuscescens. J. Plankton Res. 7: $169-173$

Thompson, T E. (1960). Defensive acid-secretion in marine gastropods. J. mar. biol. Ass. U.K. 39: 115-122

Toom, P. S., Chan, D. S. (1972). Preliminary studies of nematocysts from the jellyfish Stomolophus meleagris. Toxicon 10: 605-610

Toom, P. S., Phillips, T. D., Koch, R. B. (1976). Effects of purified components of jellyfish toxin (Stomolophus meleagris) on adensosine triphosphatase activities. Biochem. Pharm. 25: 551-555

Tursch, B. (1982). Chemical protection of a fish (Abudefduf leucogaster Bleeker) by a soft coral (Litophyton viridis May). J. chem. Ecol. 8: 1421-1428

This article was presented by Professor J. S. Pearse; it was accepted for printing on March 23, 1988 